\title{
AOR
}

Selected Papers of \#AolR2021:

The 22nd Annual Conference of the

Association of Internet Researchers

Virtual Event / 13-16 Oct 2021

\section{AS IN LIFE, SO IN DEATH: EMPLOYEE VALUES AND CONTENT PRESERVATION DURING PLATFORM CLOSURE}

Frances Corry

Annenberg School for Communication \& Journalism, University of Southern California

\section{Introduction}

Despite dominant cultural narratives about platform vitality, whether their immense global penetration or companies' overwhelming political and economic power, platform history is marked by shutdown and failure. Companies and sites shutter with an understated regularity. As they go, they often delete large swaths of user content. This has included sites from the mid-1990s, like GeoCities; networks popular in the early 2000s, like Friendster and MySpace; and platforms known in the last decade, like Vine and Google+. Other sites, like Tumblr and Flickr, have shorn off user content as their platforms have changed, due to economic or legal pressure.

As both archivists and media scholars have noted, the way that media is preserved or neglected comes to shape memory practices, and therefore processes of meaningmaking in the present (Sturken, 1997). In turn, the patterns of shutdown and deletion on these sites will come to shape the way that communities and individuals are able to reflect in the future (De Kosnik, 2016).

This paper examines the phenomenon of content deletion during platform sunsetting through interviews with 52 employees from now-shuttered platforms, including MySpace, Friendster, Vine, and others. Drawing on literature on values in technology (e.g. Friedman, Kahn, \& Borning, 2006), technological breakdown and decline (e.g. Jackson, 2014), as well as from critical approaches to platforms (e.g. Van Dijck, Poell \& De Waal, 2018), this research articulates the ways that platform employees understand the ethics of social media data deletion, and how these ethics come to shape what remains of these platforms after they close. 


\section{Method}

Participants were recruited via professional online platform Linkedln. A list of employees who had previously worked at shuttered social media platforms was developed using the Archive Team's database of closed networks. Participants were interviewed from the following networks: MySpace (19), Friendster (13), Vine (8), GeoCities (5), Bolt (2), MOC (1), Friends Reunited (1), 43Things (1), Couple (1), Foodily (1).

Semi-structured interviews were conducted over Zoom from May-December 2020. Because interviews were part of a larger project examining platform sunsetting, questions covered a participant's role at the company, their perception of user communities, the arc of the platform while they worked there, and their involvement with the platform's closure, if applicable. Most interviews lasted an hour. Interviews were examined through a grounded qualitative thematic analysis using QDA software NVivo.

\section{The New Old Wild West?}

The first section of this paper hinges around an idea that was cited frequently in interviews: that when these platforms were successful, they operated without precedent and therefore without rules. Employees felt they didn't have a "roadmap" for how to run a platform, and therefore created best practices as they went along. Interviewees frequently cited the idea that these platforms were part of the Internet's "wild west," a metaphor for the stereotypical 'lawlessness' of the $19^{\text {th }}$ century American frontier.

Drawing on these observations, I note the similarities between descriptions of the companies' "wild west" days, and the lack of guidelines that employees also described when shutting down these networks. This paper thus first suggests that as these companies were in life-with employees feeling as though they were functioning without precedent-so too do these platforms function that way in death. In turn, deletion processes are strongly influenced by the values of those who remain to shut it down, instead of an agreed upon set of best practices for platform closure.

\section{Employee Preservation Ethics}

This section describes the values-or what is considered important in life (Friedman, Kahn \& Borning, 2006)-that employees brought to the deletion of user content during platform closure. Grouped by ethical standpoint, it shows three major themes in how employees grappled with the decision to remove user data.

First, some employees believed that users would be happy if their content was removed without warning. Embarrassing content from years ago would be deleted without users needing to make decisions about that content themselves. These perceptions often drew on employees' feelings about their own online persona, as they often noted that they disliked information circulating about them online.

Others articulated ethics that drew on the public's perception of platforms. These interviewees argued that platform companies needed to engage in "good communication" with their users about content deletion, including giving adequate time 
for users to download their data. If a company didn't engage in good communication about their closure, it could erode public trust in either a parent company that owned the platform, or in platforms in general.

Finally, a third group articulated ethics that emphasized the need to preserve content, often out of allegiance to the user community or out of the belief that the platform was part of internet history. These employees drew on their personal experience with user communities to support this standpoint. These employees often advocated for particular preservation schemes, sometimes against the shutdown plans proposed by company leadership. This included donating user content to organizations like the Internet Archive, or creating a platform-based, static archive.

\section{Conclusion}

This paper examines the ethical approaches that platform employees bring to the process of platform shutdown and user content deletion. Describing the ways that platforms shutter without agreed upon rules, it extends descriptions of the internet's perceived early 'lawlessness' and applies it to the phenomenon of platform closure. In a landscape absent of rules, employees shape platform content deletion in part through personal values. In this case, ethical parameters are developed in relation to the imagined desires of individual users, the projected fallout for a company, and the previous investment of user communities.

This research contributes to literature on values and technology as well as literature that takes critical approaches to the platform environment. It shows how values shape not just the construction of technological systems, but also their breakdown. Moreover, it describes how platforms have consequences not only during the years that they thrive, but also have consequences-here, for memory practices-after their presumable death.

I conclude by noting how the values of individual actors influenced the sunsetting process toward specific ends. Indeed, this research shows how public pressure on platforms, as well as drawing on the expertise of employees that have a nuanced understanding of user communities, can positively shape what remains of these platforms after they stop functioning. In turn, I argue that platform preservation advocates could focus on these components in order to develop a system-one of conscientious conservation and purposeful deletion-that best respects the use of these materials for future reflection.

\section{References}

De Kosnik, A. (2016). Rogue Archives: Digital Cultural Memory and Media Fandom. Cambridge: MIT Press.

Friedman, B., Kahn, P. H., \& Borning, A. (2006). Value Sensitive Design and Information Systems. In P. Zhang \& D. F. Galletta (Eds.), Human-computer Interaction and Management Information Systems: Foundations (pp. 348-372). Armonk: M.E. Sharpe. 
Jackson, S. J. (2014). Rethinking Repair. In T. Gillespie, P. J. Boczkowski, \& K. A. Foot (Eds.), Media Technologies: Essays on Communication, Materiality, and Society. Cambridge: MIT Press.

Sturken, M. (1997). Tangled Memories. Berkeley: University of California Press.

Van Dijck, J., Poell, T., \& de Waal, M. (2018). The Platform Society: Public Values in a Connective World. New York: OUP. 